\title{
Research on Young University Teachers' Ideological and Political Work under the Influence of WeMedia
}

\author{
Chun-Ian GUAN ${ }^{1, a,{ }^{*}}$ \\ ${ }^{1}$ School of Electrical Power, South China University of Technology, \\ Guangzhou 510640, China \\ achlguan@scut.edu.cn
}

Keywords: Young University Teachers, WeMedia, Ideological and Political Work.

\begin{abstract}
The development of WeMedia brings opportunities and challenges to the ideological and political work of young university teachers, and WeMedia becomes a significant way for ideological and political works in China. Based on the problems and characteristics of young university teachers and the application of WeMedia in ideological and political works, this paper proposed a new methodology of ideological and political works under the influence of WeMedia, which considers changing thoughts, increasing contents, innovating forms and perfecting systems.
\end{abstract}

\section{Introduction}

Young teachers are the important part in group of university teachers, who are willing to accept new things and have greater impact on university students, so studying the ideological and political situation of young university teachers are of great importance. In the age of information technology, WeMedia has developed greatly. Because WeMedia could spread information freely, widely and in time [1], WeMedia becomes a information center, which also changing the life style and thinking mode of people. In order to understand the impact of WeMedia on the thoughts of young university teachers, this paper study the ideological and political thoughts of young teachers and the application of WeMedia in daily life, works and learning, which based on the questionnaire survey to university teachers under 40 years old. The survey respondents are from 5 universities in different area of China, and they are full-time teachers who teach different majors. This survey gave out 1048 questionnaires by stratified random sampling, and received 1007 answers and 92 suggestion. The effective rate of the questionnaire is $96.08 \%$. This is a bearer survey, which data is objective and effective.

\section{The Characteristics of Young University Teachers' Ideological and Political Situation}

From the data, it shows that the ideological and political situation of young university teachers is favorable. Many of them have positive attitude towards educational concept and their profession and partly understand the Ideological and Political work in universities. But there are also some new characteristics arising in the WeMedia period.

\section{Persist in Educational Career but not in Political Ideology}

The survey reflects that young university teachers understand education comprehensively and precisely, and they are responsible for their jobs. $86.3 \%$ of the young teachers believe that being a teacher, they not only need to teach the major, but also need to teach manners for their students. $22.7 \%$ of them think that teaching the 
major well is equal to teaching the students well. Their satisfaction of their jobs also reflects in the survey. 72.7 of them show they are satisfied with their job and most young teachers are content with their income.

However, although young teachers are devoted to their career, they are still uncertain about political consciousness. For one hand, when comes to democratic decision making in the key problem of university development, $22.7 \%$ of young teachers are will to participate, and $63.6 \%$ of them say they will participate conditionally. On the other hand, when asked their central concern, only $9 \%$ of them choose the development of university, and $91 \%$ of them choose personal career planning. It shows that young teachers are concerned about the development of universities politically but they are more concerned about the problems that related to their own benefit. Collectivism may be swayed when it is contradictory to personal interest, which reflects the confusion of young teachers in choosing collectivism or personal interest.

\section{Face their Ideological Problem Bravely, but the Solution to the Problem is Limited}

From the survey, young teachers have to undertake more mental and realistic pressure in daily life and works. It is mainly because "the duty of young teachers is heavy and the work is stressful" and "it is difficult to get teaching and research achievements". A few of the young teachers say "income" is also one of the reason of their pressure. However, although there are many problems for young teachers, the solution to those problems is limited and traditional. When asked "what will you do to release pressure", all the young teachers choose communication with "relatives and friends", which is traditional and safe. And the second choice is communicating with colleagues. Only $13.6 \%$ of young teachers would choose communicating with leaders to solve problems, and $18.1 \%$ of young teachers would choose "posting microblog or Wechat group". No one choose "professional counseling service institution" or "religion and divination".

\section{Understand the Ideological and Political Work in Certain Degree, but Unsatisfied with the Progress}

In the survey, it is asked that "who do you think is responsible for ideological and political work of young teachers", and most young teachers choose "university leaders", "ministry of publicity", "ministry of personnel", "ministry of academic", "ministry of organization" and "their own school", which shows that young teachers understand the ideological and political work objectively in certain degree.

Improving the ideological and political work of young university teachers is an important task for universities, which needs considering systematically and participating jointly. Represented by "ministry of publicity" and "labor union", young teachers know precisely about the responsibility of different ministries in ideological and political work. For example, "ministry of publicity" needs to "pay attention to young teachers and try to understand their thoughts", "set up WeMedia platform for ideological work using microblog and wechat" and "improve the publicity of teachers moral and offer an example of good teachers". For "labor union", it's their responsibility that "the teachers congress should play a powerful role in solving problems of young teachers in their daily life", which means doing the ideological and political work of young teachers not only needs to solve the ideological problems, solving the practical problems is even more important.

Nonetheless, in the question "do you think your university has paid much attention to the ideological and political work of young teachers", only $45.5 \%$ of the young teachers 
choose "yes", more than half of them think universities didn't attach much importance to the ideological and political job, which shows that young teachers are not satisfied with the practical situation of the ideological and political work and universities didn't pay much attention to the work. On the other hand, young teachers learn political theories from "learning together with colleagues in the same department", "arranged lessons by party branch" and "internet platform". For related departments, the responsibility of ideological and political work isn't undertaken completely. Methods for young teachers to learn political theories are limited.

\section{The Effect of WeMedia on the Ideological and Political Work of Young Teachers}

Represented by forums, microblog and wechat, WeMedia has been applied in every aspects in our daily life, which changes people's life, jobs, learning ways and thoughts greatly, and it's also changes the ideological and political work of young teachers in universities.

\section{WeMedia Becomes an Important Way for Young Teachers' Ideological and Political Work}

The survey shows that WeMedia like QQ, wechat and microblog has been applied in young teachers' daily life extensively. All the young teachers have more than 2 WeMedia, and $81.8 \%$ of them have 3 WeMedia. Using WeMedia has become an important activity in their daily life. $50 \%$ of the young teachers pay more than 4 hours in WeMedia. Only $22.8 \%$ of the young teachers use WeMedia no more than 1 hour.

From the data, young teachers are more concerned about political news. $27.3 \%$ of them say they are very concerned about it, and most of them acquire news from wechat $(77.2 \%)$, computer(72.7\%), news $\operatorname{App}(50 \%)$, microblog(40.9\%), and so on. Because of its openness, flexible and interactivity, WeMedia is accepted by most young teachers. WeMedia turns into a significant medium for young teachers to receive news, express personal thought and spread political culture, and it is also become an important way for ideological and political work.

\section{Young Teachers Feel Contradictory when Using WeMedia}

There is contradictory thought of young teachers when using WeMedia. On one hand, all young teachers are very concerned about state news in WeMedia, and there are more than $90 \%$ of the young teachers focusing on the news related to universities. $59 \%$ of them follow the microblog and wechat of their universities themselves. On the other hand, few of young teachers would comment on the news in WeMedia. Only 9\% of them say they would comment on the state news, and those who will comment on the news that related to universities are reduced to $4.5 \%$. In the same time, $81.9 \%$ of the young teachers choose not to expose improper words or deeds of leaders in WeMedia, and $59 \%$ of them won't upload the news of their universities. Since the information from internet is diverse and illusory, young teachers are cautious about accepting and spreading information in WeMedia.

\section{The WeMedia Application Problems Existing in Young Teachers' Ideological and Political Work}

Firstly, the function of WeMedia has not been made use of fully. The survey shows the political learning ways for young teachers mainly are "learning together with department colleges", "learning lessons arranged by party branch" and "internet platform", but these ways for young teachers to improve political learning effect are not 
that evident. And acquiring news related to universities from "university website" is all the young teachers' first choice; only $13.6 \%$ and $27.2 \%$ of them would choose "university microblog" and "university Wechat" to obtain information. There are no integrated systems to do ideological and political work of young teachers on WeMedia. The information on WeMedia is scattered, unreadable and lack of guidance. As an important new method to do ideological and political work, the effect of WeMedia needs to enhance.

Secondly, young teachers use WeMedia passively. The survey shows that all the young teachers have more than $2 \mathrm{WeMedia}$. But to the news related to our country or universities, they choose to focus, but not comment on it. To the misconduct of leaders and the new things, most young teachers won't upload it on the social network. These behaviors reflect that young teachers don't give insight into the new method of ideological and political work, WeMedia, and it also reveals the fact that young teachers use WeMedia passively, which means they won't spread information actively. The reason for their behavior is mainly because WeMedia is "no entry barrier" and "interactive", making different culture, perceptions and values are mixed in WeMedia. In addition, there is no regulator from universities on WeMedia, which makes WeMedia lack of credibility. So the attitude of young teachers to WeMedia is conservative and suspicious.

\section{Suggestions for Improving Young Teachers' Ideological and Political Work in WeMedia Period}

Combining the practical situation of young teachers' ideological and political work and the effect of WeMedia on the ideological and political work, it needs considering concepts, contents, forms and institution comprehensively to improve young teachers' ideological and political work in WeMedia period.

\section{Change the Concept of Ideological and Political Work, Establishing the Foundation for WeMedia Work}

In WeMedia period, there are new requirements for young teachers' ideological and political work. It needs to understand the opportunities and challenges brought by WeMedia, establish the educational philosophy that we should combine ideological and political work with WeMedia, change the conservative concept of ideological and political work, insist on improving the contents, have reasonable regulator on WeMedia, insist the educational philosophy of intersubjectivity[2], highly value the application of WeMedia in ideological and political work, make WeMedia related with ideological and political work freely, equally and harmoniously and establish the base of WeMedia work, only in this way can we do the young teachers' ideological and political work well.

\section{Enrich the Ideological and Political Education; Augment the Function of WeMedia to the Ideological Work}

To improve the effectiveness of ideological and political work, the key element is making the ideological work substantial and active. There is abundant of information on the WeMedia. For one side, this information offers a lot of material for young teachers' ideological and political work. For another, it also requires young teachers have greater ability to recognize the contents. The young teachers' ideological and political work should base on the characteristics of young teachers' thoughts and the needs of them. It also needs to improve the learning of political theories and 
professional ethics, have firm political stand and pay more attention to choose appropriate contents to guide ideology. In the same time, to enrich the contents of young teachers' education on WeMedia, it requires to improve the ability of WeMedia operator, such as how to choose, understand, object, evaluate and create media information, which enhance the ideological guidance function of WeMedia from the perspective of contents.

\section{Create New Forms of Ideological and Political Work, Make Use of WeMedia Platform for Communication}

WeMedia builds a convenient way for different people to communicate about the ideological and political work. Understand everyone' s obligation in ideological and political work, turn WeMedia like wechat and microblog into communication platform, connect more people together, create new learning forms of political theories and increase the communication between young teachers and related department that doing the ideological and political work. On one hand, aiming at the characteristics of young teachers, make full use of WeMedia technology and education resource to prepare the contents of ideological and political work. On the other hand, focus on the comments declared by young teachers, understand their thoughts and create new communicating and learning forms, by which make full use of WeMedia.

Establish the Supervision System of Ideological and Political Education, Standardize the WeMedia Operating Environment

Let WeMedia play an active role in young teachers' ideological and political education. Establish the supervision system of ideological and political education and standardize the WeMedia operating environment to guide public opinion. Organize supervision team consisting of colleges from ideological and political education department for WeMedia. Enhance coordination in the team. Based on clear division of labor, WeMedia management system and moral rules, systematically establish the supervision and interventional mechanism, feedback and warning mechanism [3], by this way to standardize the WeMedia operating environment of ideological and political work.

\section{References}

[1] Y.M. Dai, An Interpretation of the We Media from the Perspective of Communication Studies (In Chinese), Journalism and Communication, 5(2011):4-11.

[2] X.F. Yang, Research on Ideological and Political Education Innovation in the Media Age (In Chinese), Anhui University, 2014.

[3] X.T. He, The Research on the Ideological and Political Education Function of the WeMedia and its Optimization (In Chinese), Tianjin Normal University, 2015. 